\title{
Making Touristic Areas Aesthetic According to Opinions of Gifted Students
}

\author{
Mehmet Ali Genç \\ Division of Art Education, Konya Necmettin Erbakan University, Turkey
}

Copyright $\bigcirc 2016$ by authors, all rights reserved. Authors agree that this article remains permanently open access under the terms of the Creative Commons Attribution License 4.0 International License

\begin{abstract}
Architectural structures, historic areas, museums, parks, streets and alleys, cultural and social sites in the cities are an important aesthetic element. The most basic element of tourism is to make a situation or space aesthetic. For this purpose, spaces are often restored and tried to make them attractive to the tourism. It is well known that the gifted students (ÜYÖ) pioneered for the development and progress in the society also develop their aesthetic aspects, as well as having their special abilities to produce new and genuine products and opinions. In this study, it was aimed to examine which opinions the gifted students (ÜYÖ) hold to enrich the city we live in an aesthetically manner. To that end, it was taken students' opinions about architectural structures, historic areas, museums, parks, streets and alleys, cultural and social sites. The study was performed with a qualitative approach. In accordance with this purpose, it was received the opinion of 29 gifted students. The gifted students' age has ranged from 13 to 15.13 of them are female and 16 male. Research data were obtained by means of the face to face group interviewing. Firstly of all, it was brainstormed for each heading. In the second session, outstanding opinions were discussed. Data were analyzed by descriptive analysis and content analysis method. Results were explained by $\%$ and frequencies. As a result of this study, it was determined relevant students' opinions about making architectural structures, historic areas, museums, parks, streets and alleys, cultural and social sites attractive in terms of tourism. Original opinions were revealed by comparing students' opinions with existing applications.
\end{abstract}

Keywords Gifted students, Tourism, Aesthetic Destinations

\section{Introduction}

Tourism which makes travels through reasons such as recreation, entertainment, curiosity, culture and gaining experience is an important sector for countries [1]. Gradually increasing the travels that aim to get to know people from different cultures and to get on-site information about the cultures of different societies has boosted the cultural richness at the destinations and invigorated the economy.

They are made more aesthetic for tourism by reconstructing architectural structures, historic areas, museums, parks, streets, alleys, cultural and social areas, found in the cities as an aesthetic element to that city. These reconstructions form the aesthetic of the city in a process that is shaped by social, cultural or economic characteristics of communities [2]. Cities produce creative solutions for city aesthetics in order to attract more visitors, or tourists [3].

Arrangement considering concern for the beauty of places and beautification of the environment in which people live requires aesthetic sensibility. Gifted students are the leading individuals who develop aesthetic sensibility within the society. They are interested in them by fast apprehending aesthetic features since sense of beauty develops in these students [4]. Other key features of gifted students (UYÖ), who pioneer social development and progress, include being ahead of their peers in physical, mental, and learning terms [5]bringing original ideas or innovations to and having their high motivation, determination or ability to solve problems[6].

This study aims to examine which views gifted students (ÜYÖ) hold aesthetically to render Konya attractive to tourism. Research results are determined students' opinions about making architectural structures, historic areas, museums, parks, streets, and alleys, cultural and social areas aesthetically attractive. Original ideas produce by comparing student views with existing applications.

\section{Konya and Tourism}

People aim to recognize people from different cultures, to see tangible and intangible cultural values in different communities and to get on-site information on these values through tourism [7]. It has increased the importance of historical places, museums, historical ruins or remains, customs and traditions thanks to great interest shown in 
cultural heritage [8]. It turns into a mechanism for protecting natural environment, local culture and artistic assets when the tourism which has a deep influence upon society, economy, natural and cultural environment of a region properly develops and manages [7].

It has begun to make tourism competition obligatory among cities in the world so that cities are favoured by people and made them into a point or centre of attraction [9]. Thus, a great effort is made to preserve and develop cultural property transmitted from generation to generation by inheritance to enhance the attractiveness of cities [7].

Each city possesses its unique characteristic with historical accumulation and with social, cultural and commercial background that contains within itself [10]. Konya whose origins date back to the first settlement period of history of humanity is an important city that was the capital to Seljuk Empire [3].

Konya, which also has a significant potential in tourism, is located in an important transition route. Moreover, it has always had an important city when examined from a historical perspective [9]. Konya city that offers its historical richness to domestic and foreign tourists [8] has the characteristics of a place open to cultural tourism-oriented spatial and functional developments through spatial and functional patterns that are formed to the accompaniment of cultural heritage values [11].

\section{City and Aesthetics}

Aesthetics that means perception and sense is defined human as comprehension and perceiving of something beautiful by way of perception and sense [12]. When it is considered within the scope of the environment, environmental aesthetics means to beautify the environment or to be interested in beautiful environment [13].

Open-green areas, courtyards, gardens, roads and squares are an integral part of urban aesthetics. Lines, colours and textural properties that make up the surfaces of elements in urban environments, and buildings' facade proportions, quality of openings and facade decorations are also important factors in determining the quality of the urban environment. In addition to this, elements such as floor coverings, urban equipments, lighting equipments, stops and billboards, and plant material and its usage patterns are factors that make a direct contribution to urban aesthetic. With a combination of all these values, city shape and city silhouette relating to the whole of city are created, and urban aesthetics and attractiveness emerge [12].

Historical buildings constitute the basic characteristics of cities. These buildings are considered to be determinative city silhouette. In addition with architectural structures, open-green areas and their interrelations are also determining the character of a city [14].

The world's most tourist destinations are regarded to be cities, which have historical and cultural values and are an aesthetically rich appearance [15]. Cities should give aesthetic pleasure rather than discomfort to people, who sightsee and search. Aging of objects, their peeling paint and incompleteness in visually unfavourable physical environments create psychological unrest and may also cause indirect psychological effects on individuals [16].

Artistic activities have constantly occurred throughout formation and development of the cities, and city and art has always been in a relationship. One of the best ways to reconstruct squares and streets of a city, namely its surroundings, eliminate the aesthetic deprivation of the buildings and ensure unity compatible with the environment is likely that artistic works are situated at open areas [17]. Monuments and plastic elements used often in especially public squares or in a place required to attract considerable attention are making their designment more effective and perceptible through color, form, shape and measurement qualifications that enhance the visual value of urban spaces[18].

Green areas are also another element of the urban aesthetics. Green areas become indispensable spaces where cities will be respired and freshened up [19]. Green areas are named open areas and mass and fragmental green areas outside of architectural structures (block stacks, buildings and hard surfaces) within the urban texture as a complement of integrative and separative functional aesthetic systems [20]. In addition, ornamental trees provide effective and pleasant green areas by creating identity and continuity in parallel with functional and aesthetic contributions to spaces [14].

\section{Method}

The study was carried out with a qualitative approach and screening model. This study was aimed to examine what kind of views students identified as gifted hold to aesthetically enrich the city in which they inhabit. For this purpose, it was received students' opinions about aesthetic regulations in architectural structures, historic areas, museums, parks, streets, and alleys, cultural and social areas.

\subsection{Study Group}

The study group consisted of gifted students in Konya Science and Art Center, which provides training for gifted students. In accordance with this purpose, it was taken 29 gifted student's opinions. Gifted students were composed of 13 schoolgirls and 16 schoolboys, all of whom are in the age range of 13 to 15 . Easily accessible convenience sampling method of purposive sample methods was used to create the study group.

\subsection{Collection and Analysis of Data}

Konya that has an important potential in tourism is a significant space in respect of cultural heritage. It is attempted to reorganize the spaces here for tourism. 
Reorganization of these spaces without considering the beauty anxiety requires aesthetic sensitivity. Students known to be gifted are the primary in individuals whose aesthetic sensitivity developed in society. For making Konya attractive in respect of tourism, it is attempted to examine which opinions the gifted students have. For that purpose, a study tour was organized to the historical and touristic places of Konya together with students. Students have been interviewed by using "Student Interview Form" after the tour. During the process of the "Student Interview Form" first the literature related to topic was reviewed and titles and items to be included in form have been determined. After taking the opinions of those specialists in their fields, it was put the last touches on form.

In this form which consists of four open-ended questions, it was aimed to find answer to questions such as "what sort of architectural structures, museums, historic areas, parks, cultural and social areas do students know touristically?", "what are touristic areas in Konya aspects seeming beautiful and unsightly?", "what types of opinions do they hold about environmental planning of historical buildings?", and "what types of arrangements will they make so that touristic destinations make attractive and bring in the tourists?"

Research data were obtained by face-to-face group interviewing. Data were analyzed by way of descriptive analysis and content analysis method. Research findings were explained by $\%$ and frequencies.

\section{Results}

Famous or interesting places, spaces or sights that have been attracting gifted students's attention in Konya were Karatay Madrasa, İnceMinareli Madrasa, Mevlana Museum, Alaladdin Mosque, Sırçalı Madrasa Koyunoğlu Museum, archeological museum, ethnographic museum, Kültür Park, Alâeddin Park and The Valley of the Butterflies, respectively.

Answers given by gifted students to aspects seeming beautiful of tourist areas in Konya are presented in Table 1.

Table 1. Frequency and Percentage Distributions of Answers Given by Gifted Students to the Question "What are aspects seeming beautiful of the touristic areas in your opinion?"

\begin{tabular}{|c|c|c|}
\hline & f & \% \\
\hline A spacious and clean environment & 8 & 27.58 \\
\hline Constitution of squares (open areas) & 6 & 20.68 \\
\hline Restoration & 6 & 20.68 \\
\hline Reforestation & 5 & 17.24 \\
\hline A well-maintained environment & 5 & 17.24 \\
\hline Area lighting & 1 & 3.44 \\
\hline Total & 29 & 100 \\
\hline
\end{tabular}

Students indicate that touristic areas look beautiful themselves through expressions such as "I really like that tourist attractions is clean", "I saw that touristic areas are both clean and spacious", "especially I like to widen the area in front of Mevlana" and "Parks are clean but education is a must for polluters". They state that newly-created squares look beautiful themselves through expressions such as "Newly-created squares enable touristic areas to be spacious. They are also nice to be clean", "I like squares. I am walking there. There is no traffic. If only such places further increase". They use such expressions "I really like to restore them in order to protect historical and touristic areas", "It is nice to protect by restoring historic buildings. If only every historical building could renovate". They indicate that plantations look good with such expressions "I like to afforest touristic places". "It has more attractive to plant with trees in historic areas than before". They report to admire the afforestation of touristic areas with such expressions "I really like caring the trees and pruning them so as not to prevent people from passing there", "It is better not to plant trees if any care is not made". "I like to clean and maintain well the pavements and benches/seats".

Answers given by gifted students to aspects seeming unsightly of tourist areas in Konya are presented in Table 2.

Table 2. Frequency and Percentage Distributions of Answers Given by Gifted Students to the Question "What are aspects seeming unsightly of the touristic areas in your opinion?"

\begin{tabular}{|c|c|c|}
\hline & f & \% \\
\hline $\begin{array}{c}\text { Being put historic buildings in the shade by new } \\
\text { buildings }\end{array}$ & 7 & 24.13 \\
\hline Visual pollution & 8 & 27.58 \\
\hline The lack of resting areas for visitors & 5 & 17.24 \\
\hline Intense vehicle traffic & 4 & 13.79 \\
\hline The lack of shade & 3 & 10.34 \\
\hline Being neglected environmental cleaning & 1 & 3.44 \\
\hline The lack of spacious and clean environment & 1 & 3.44 \\
\hline Total & 29 & 100 \\
\hline
\end{tabular}

Students pass an opinion that they do not seem beautiful to overbuild very close to historic buildings by such expressions "I really annoy me when new buildings construct very close to historic buildings. Because these new buildings put historic buildings or ancient monuments in the shade in my opinion", "Such a surrounding reduces the magnificence of historic buildings" and"the fact that new buildings construct very close to historic buildings suggests the congestion. I am sometimes putting myself in historic buildings". They pass their remark on visually unpleasant spaces with such expressions "Advertising sign boards on streets and intersections repulse me. I guess tourists also do not want to see these signboards" and "The use of bright and vibrant lights distract visitors' attention". They want to draw attention to the lack of resting places by such expressions "Absence of places to be rested for tourists coming to visit is a lack", "Benchs should be put on certain places to sit tired people when going to visit the sights". And what's more, students have tried to attract the attention to intense vehicle traffic with such expressions "It is unpleasant to go the traffic into place very close to historical buildings" and to the lack of shade with such expressions "In the summertime, sun is 
very uncomfortable in touristic places".

Answers given by gifted students to environmental planning of historical buildings in Konya are presented in Table 3 .

Table 3. Frequency and Percentage Distributions of Answers Given by Gifted Students to the Question "What would you want to say about the environmental planning of historical buildings in Konya?"

\begin{tabular}{|c|c|c|}
\hline $\begin{array}{c}\text { Environmental planning is not compatible with the } \\
\text { historic buildings. }\end{array}$ & f & \% \\
\hline $\begin{array}{c}\text { There has been no adequate arrangements for places to } \\
\text { rest the visitors. }\end{array}$ & 6 & 27.58 \\
\hline $\begin{array}{c}\text { The surrounding area of historic buildings has not been } \\
\text { greened sufficiently. }\end{array}$ & 5 & 17.24 \\
\hline $\begin{array}{c}\text { Visual art elements do not include in environmental } \\
\text { planning. }\end{array}$ & 4 & 13.79 \\
\hline $\begin{array}{c}\text { The surrounding area of historic buildings is surrounded } \\
\text { by parked cars. }\end{array}$ & 2 & 6.89 \\
\hline $\begin{array}{c}\text { Our historical monuments are engulfed in excessive } \\
\text { forestation. }\end{array}$ & 2 & 6.89 \\
\hline Lighting of historical buildings is not enough. & 1 & 3.44 \\
\hline Environmental cleanup is insufficient. & 1 & 3.44 \\
\hline Historic buildings are well-preserved & 1 & 3.44 \\
\hline Total & 29 & 100 \\
\hline
\end{tabular}

Students highlight that environmental planning is not compatible with the historic buildings with such expressions "The colors used in environmental planning should be compatible with those of the historic buildings", "Landscaping should comply with our historic buildings", "The tourists who come to visit Konya should feel the culture of Konya by looking at the landscaping" and "Work of art should be placed on certain points, such as monument and embossed images, which will inform tourists who come to visit historical buildings". They catch the attention to the absence of adequate arrangements for visitors in touristic areas by such expressions "There is no rest areas of coming visitors around the places that attract intense visitor" and "Seatings should be built the spaces in order to attract more visitors". They address the absence of enough green fields around the historic buildings with such expressions "The surrounding area of historic buildings has not been greened sufficiently", "These places could be more attractive for tourists if greened", "There are less green areas around the architectural structures" and "Our stress is reduced through green-fields, however, and we are very happier than before". They indicate such their expressions "It can benefit from visual arts representation about historic buildings. This attracts the attention of tourists, too" and "Monument, sculpture or embossed pictures both glamourize the environment and give information about the history. If only these might be performed". They mention that cars parked around the historic buildings disturb visitors or others with such expressions "Pedestrians are under the attack of cars parked on the pavement" and "It seems as if turned into the car park around the historic buildings".

In the event of providing opportunity for students, answers given by them as to what types of arrangements will they make in touristic destinations in the city they live are presented in Table 4.

Table 4. Frequency and Percentage Distributions of Answers Given by Gifted Students to the Question "what types of arrangements will they make so that touristic destinations make attractive and bring in the tourists?"

\begin{tabular}{|c|c|c|}
\hline & f & $\%$ \\
\hline $\begin{array}{l}\text { I make environment arrangements compatible with the } \\
\text { historic buildings }\end{array}$ & 6 & 20.68 \\
\hline I eliminate the visual pollution. & 5 & 17.24 \\
\hline I increase green fields. & 5 & 17.24 \\
\hline $\begin{array}{l}\text { I build up recreational areas in the places where visitors } \\
\text { attract. }\end{array}$ & 4 & 13.79 \\
\hline I decorate the spaces with the visual arts elements. & 4 & 13.79 \\
\hline I remove the traffic from the touristic locations. & 3 & 10.34 \\
\hline I illuminate the spaces suitably. & 1 & 3.44 \\
\hline I protect touristic destinations properly. & 1 & 3.44 \\
\hline Total & 29 & 100 \\
\hline
\end{tabular}

Students point out that they will create a environment compatible with the historic buildings while making environment arrangements through such expressions "I include some attributes related to the history of Seljuk and Ottoman culture, for example sculpture, in environmental planning", "I choose pavements, fountains and seats used in environmental planning in accordance with architectural structure" and "I construct works of art such as houses, madrassa, museums, sculptures and embossments around the historic buildings with motifs and colors". They say to be removed the visual pollution with such expressions "I bring a certain arrangement for base stations, dish antenna and advertising sign boards", and "worn-rugged paving stone, advertising sign boards and improper illumination of pavements break the aesthetic. I fixed these aesthetically environmental problems". They address to increase green areas with such expressions "To green around the historic buildings makes the places more aesthetic and functional. I ornament these places with green fields and tulips for this purpose" and "I make those parts more attractive by greening walks/roads and touristic places". They indicate to create recreational areas by such expressions "I design the places to be rested them for a while after tourists go and see while making the environmental arrangements for the historic buildings", "walking visitors are tired and want to sit and have something to drink. I would provide it in touristic destinations" and "I fill this deficiency so that walking tourist enjoys getting around after resting". Students say that they will decorate touristic places with visual art elements with such expressions "I want to see the works of art around me. For example, I can make a model of Konya Castle", "I utilize angel figures and dragon figures used in Konya Castle in touristic places" and "I increase artworks, which give different messages to them while tourists go to visit our city: For example, monuments, sculptures, wall paintings and pictures in floor coverings". Students state that they will remove vehicle traffic from touristic destinations with such expressions "I transfer heavy traffic to other directions to 
protect the natural and cultural properties" and "I do not allow other vehicles except for public transport vehicles to go into historical places since confusion distracts tourists' attention and eliminates the impact of historical climate".

\section{Discussions, Conclusions and Recommendations}

It has been concluded that the gifted students whose aesthetic sensitivity developed loved the refreshing and clean environment of touristic areas, construction of squares (open spaces), restoration of works, environmental forestation and maintenance. The same students are considered being put historic buildings in the shade by new buildings in touristic areas, visual pollution in the environment, and lack of adequate resting areas for visitors in touristic areas, heavy vehicle traffic and the lack of shade as unpleasant aspects.

It is recommended to use the opinions of the gifted students whose aesthetic sensitivity in society developed best. It is recommended that while making arrangements for touristic places, new buildings should not be built very close to the historic buildings and these new ones should erect at a distance not to affect historic buildings' magnificence and attractiveness. It is underlined, however, that ancient and historic areas, which exhibit historical periods and architectural characteristics in this manner, can also be protected without disrupting [21]. It is also suggested that new plannings should do to eliminate the elements, which lead to visual pollution. It is proposed that areas visited intensively by visitors are freed from vehicle traffic and rested-shade places for visitors are created there.

It has been reached the conclusion that environment arrangements made are not compatible with the historic buildings, adequate arrangements for the rest of the visitors are not found, sufficient greening is not made around the the historic buildings and visual art elements do not include in environmental planning.

It is proposed that when making the environmental planning for the historic buildings, these plannings should be in line with the historic buildings and it should be greened sufficiently around the historic buildings. Kurdoğlu and Pirselimoğlu[14] stress that the promotion of cities with green pattern will be able to make the environment more aesthetic and functional. It is suggested that visual art elements include in environmental planning of historic buildings. The plastic artworks used in open-spaces are objects with great aesthetic value, as well as representation features such as locator and marker. Furthermore, open-space plastic artworks that add new meanings to the urban culture are used for different purposes according to culture and requirements of spanned periods [22].

Solutions offered by students to touristic places are listed as compatible of environmental plannings with the historic buildings, eradication of visual pollution, increase in green areas, and the creation of rest areas where the visitors attract, adornment of visual art elements with touristic places and removal the traffic from touristic places. They have demonstrated their creativity and aesthetic capacities with these solution recommendations that gifted students propose to the arrangement of touristic places.

\section{REFERENCES}

[1] İ. Güngör, M. Çuhadar, Estimation of the Demand of the German Tourists for Antalya City through Artificial Neural Networks, Journal of Commerce \& Tourism Education Faculty, Vol. 1, 84-97, 2005.

[2] Y. Aksoy, Discussion of Open Green Areas of Üsküdar County, Ecology, Vol. 52, 38-44, 2004.

[3] N. Görkemli, B. Solmaz, Role of the Science Centres on City Branding and the Konya Sample, Journal of Communication, Theory and Research, Vol. 34, 98-109, 2012.

[4] A. Ataman, Gifted and Talented People, Anadolu University Press, Eskişehir.

[5] H. Akkanat, Gifted and Talented People (Editors Mustafa Ruhişirin, Adnan Kulaksızoğlu, Ahmet Emre Bilgili), Selected Papers Book on Talented Children, Çocuk Vakfi Press, İstanbul, 2004.

[6] D. Boland, Artistically Talented Students: A Call for Research, Working Papers in Art Education, Vol. 5, No.1, $16-25,1986$.

[7] A. Avan, Assessment of Purchasing Processes of Foreign Tourists visiting Konya for Cultural Purposes, Kocatepe University, Institute for Social Sciences, Master Program, AfyonKarahisar,2010.

[8] T. Tapur, Cultural and Religious Tourism in Konya City, Journal of International Social Researches, Vol. 2, No 9, 473-492,2009.

[9] M. Toksarı, İ. İsen, A. Dağcı, Branding and Marketin Process of a City: An Application in Konya City, Niğde University İ̈BF Journal, Vol. 7, No 1, 328-343, 2014.

[10] N. Görkemli, G. Tekin, Y. Baypınar, Cultural Activities and City Image- Opinions of Target Masses related to Affects of Mevlana Celebrations on the City Image of Konya, Gümüşhane UniversityJournal of the Faculty of Communication, Vol. 2, No 1, 150-171, 2013.

[11] K. Özcan, An Approach Recommendation on Feasibility of Sustainable Urban Protection: City Centre Sample of Konya History, Ecology, Vol. 26, No 2, 1-18, 2009.

[12] E. Erdoğan, Environment and Urban Aesthetic, Journal of Bartin Faculty of Forestry, Vol. 8, No 9, 68-77, 2006.

[13] G. Ceylan, Comparison of Perspectives of Secondary School Grade 10 Students receiving and not receiving Visual Arts Education on their Environment where they live, Gazi University, Institute for Educational Sciences, Master's Thesis, Ankara, 2008.

[14] B. Ç. Kurdoğlu, Z. Pirselimoğlu, A Study on towards Semantic Assessment of Path Trees, Çoruh University, Journal of Faculty of Forestry, Vol. 12 No 2, 211-221, 2011. 
[15] Y. Göğebakan, Affect on Aesthetic and Urban Construction, İnönü University, Journal of Art and Design, Vol. 2, No 4, 73-84, 2012.

[16] H. İz Bölükoğlu, Visual Pollution and Art Education, KKEFD, Vol.8, 101-112, 2003.

[17] M. Güç, Contribution of Open Area Sculptures on Urban Aesthetic, Çukurova University, Institute of Social Sciences, Master's Thesis, Adana, 2005.

[18] L. Güremen, Research of Urban Furniture in respect of Urban Identity and Urban Aesthetic Specific to Amasya City, Journal of New World Sciences Academy, Vol. 6, No 2, 254-291, 2011.

[19] N. Kuter, Urban Aesthetic and Cankırı Sample, Kastamonu
University, Journal of Faculty of Forestry, Vol. 7, No 1, 38-53. 2007.

[20] Ö. Yerli, G. Kesim, Discussion of Aesthetic and Functional Aspects of Urban Corridors: A Düzce Sample, Ankara University, Journal of Environmental Sciences, Vol. 1, No 1, 1309-1107, 2009.

[21] H. Susmaz, C. Ekinci, Fundamentals of the Healthy Urbanization Process, Journal of Social Sciences, Vol. 4, No 1, 21-43, 2009.

[22] A. Taşkıran, Contribution of Plastic Artworks to City Aesthetic and City Culture in urban space (Antalya sample), Çukurova University, Institute of Science, Journal of Faculty of Forestry Master's Thesis, Adana, 2010. 